\title{
Real Time Monitoring with Indigenous Peoples: Technical, Social and Political Challenges, and Lessons from Brazil
}

\author{
Alex Shankland, Maria Elvira Toledo, Adriana Barbosa and \\ Maria Ferreira Bittencourt
}

\begin{abstract}
The government of Brazil has introduced two health and nutrition monitoring systems (the Indigenous Health Care Information System (SIASI) and the Food and Nutrition Surveillance System for Indigenous People (SISVAN-I) as part of reforms to health care and social protection services for indigenous peoples, who have the worst health status of any population group in the country. This article covers the origins and development of these systems and examines their functioning in one local health district, which serves the Xavante people. It assesses the systems' performance in relation to the aspects established in the case study terms of reference: quality of information, inclusivity, relevance to potential users, costs and sustainability. $A$ number of key issues are identified. Some are intrinsic to the technical, cultural and political challenges of working with indigenous peoples, while others reflect problems with the implementation of responses to these challenges at different levels in Brazil.
\end{abstract}

\section{Introduction}

Health and nutrition inequities in Brazil are well documented and affect indigenous people more than any other population group (Consórcio IDSSSL-Cebrap 2009). Brazil is not unique in this regard, as indigenous peoples worldwide tend to have a significantly worse health status than majority populations in rich, middle-income and low-income countries alike (Oosterhoff et al. 2012). Studies have revealed such severe disparities in progress towards achieving the MDGs among indigenous and non-indigenous populations across the world that a review article in The Lancet found that indigenous peoples were 'behind everyone, everywhere' (Stephens et al. 2005).

The government of Brazil is highly committed to addressing these inequities and has established a specific Indigenous Health Care Subsystem (Subsistema de Atenção à Saúde Indígena, SASI) of the national health system (Sistema Único de Saúde, SUS) in order to guarantee indigenous peoples' access to health services. The government has also launched a number of initiatives under the aegis of the Ministry of Social
Development and the Fight against Hunger (Ministério do Desenvolvimento Social e do Combate à Fome, MDS) to combat both chronic and acute undernutrition among indigenous children. Several of these measures have received support from the Joint Programme on Food and Nutrition Security for Indigenous Children and Women, which is supported by UNICEF, working alongside FAO, ILO, WHO/PAHO and UNDP.

This case study examined the current and potential capacity of the health and nutrition monitoring systems of Brazil's SASI to support Real Time Monitoring for the Most Vulnerable (RTMMV). It combined national-level analysis of policy and systems with a focus on the specific experience of their implementation in one set of indigenous territories: those inhabited by the Xavante people, who have been found to have some of the country's highest rates of infant mortality and undernutrition (Guimarães de Souza et al. 2010). In line with UNICEF Brazil's own objectives in its work with the Joint Programme, the study sought to draw on Brazil's experience to identify wider lessons for RTMMV 
with indigenous peoples. This is of particular relevance to an equity-based approach to addressing vulnerability, given that indigenous peoples account for perhaps a third of the world's 'bottom billion' poorest people (Shankland 2011).

The article begins by outlining the health, nutrition and vulnerability issues faced by indigenous peoples in Brazil and the Brazilian government's policy responses to these issues. It goes on to describe the study focus area and the case study process, before providing a detailed description of the key health and nutrition monitoring systems. The case study findings are then presented in relation to the aspects established in the RTMMV project's terms of reference: quality of information, inclusivity, relevance to potential users, costs and sustainability. The concluding section discusses the wider relevance of the key issues identified in Brazil to the technical, cultural and political challenges of working with indigenous peoples to ensure effective real-time vulnerability monitoring.

\section{Indigenous peoples, health and vulnerability in Brazil}

\subsection{Indigenous demography and health status}

Brazil's indigenous groups suffered devastating social, epidemiological and demographic impacts as a result of European colonisation. Since the latter part of the twentieth century the indigenous population has begun to grow again, but it still represents less than half of one per cent of Brazil's total population. The 2010 Census recorded a total of 734,000 people identifying themselves as indigenous, with perhaps a third living permanently or temporarily in urban areas and the remainder in the country's 579 recognised indigenous territories. These territories together cover some 12 per cent of Brazil's land area, but they vary enormously in size from small, crowded settlements in the south or northeast of the country to vast forested areas in the remoter regions of the Amazon; not all are yet officially demarcated, and levels of land conflict remain high, particularly in areas along the country's expanding agricultural frontier.

Brazil's indigenous population is extremely diverse, consisting of no fewer than 225 different indigenous peoples speaking some 180 different languages, with only three ethnic groups numbering more than 20,000 people and many smaller groups who remain extremely vulnerable to demographic collapse or even at risk of extinction (Azevedo 2009). While reliable demographic and epidemiological data are hard to come by, the indigenous population appears to be undergoing a complex epidemiological transition. Morbidity and mortality from infectious diseases and persistently high levels of child undernutrition coexist with a rising prevalence of non-communicable diseases including cardiovascular diseases and Type 2 diabetes. Chronic undernutrition has led to stunting rates calculated as between 16 per cent and 53.5 per cent by a range of recent studies (Paes de Sousa and Menegolla 2009: 43). Despite the overall picture of demographic recovery, the high birth rates recorded in recent years have been combined with high levels of infant mortality. Official figures are highly contested, but recent estimates of the infant mortality rate have averaged 80 per thousand live births, approximately four times the figure for the Brazilian population as a whole (Azevedo 2009).

Indigenous morbidity and mortality data reflect a complex and interlocking web of vulnerabilities, which until recently have been subject to a 'problematic demographic and epidemiological invisibility' (Coimbra and Santos 2000: 131). Over the last decade, however, Brazil has made significant efforts to address this 'invisibility', establishing targeted health care, nutrition support and information systems.

\subsection{The Indigenous Health Care Subsystem}

Brazil's national health system (Sistema Único de Saúde, SUS) follows a rights-based approach to ensuring universal access, underpinned by principles of universality, participation, decentralisation and integrated care established by the 1988 Constitution and 1990 Basic Health Law. Since the 1990s it has secured major advances in coverage and improvements in maternal and child health (Victora et al. 2011). However, improvements in access and outcomes among indigenous peoples have lagged behind those for the population as a whole, resulting in health inequalities that have been the focus of increasingly vocal protests on the part of indigenous peoples' movements and their allies in academia and civil society.

In 1999, a change in the law took responsibility for indigenous health care away from the 
Indigenous Affairs Agency (Fundação Nacional do Índio, FUNAI) and established the Indigenous Health Care Subsystem (Subsistema de Atenção à Saúde Indígena, SASI) of the SUS, under the responsibility of the Ministry of Health. Initially the National Health Foundation (Fundação Nacional de Saúde, FUNASA) was responsible for the management of the SASI. However, poor performance and several corruption scandals led to a transfer of the management responsibilities to the newly established Special Secretariat for Indigenous Health (Secretaria Especial de Saúde Indígena, SESAI) in 2010. This triggered a long and complex transition process; at the time of the study SESAI was still in the process of consolidating its management structures and institutionalising its links with other parts of the health system, and had only recently completed the process of taking over responsibility for all aspects of the SASI (Benevides and Portillo, forthcoming).

The SASI is organised into 34 Special Indigenous Health Districts (Distrito Sanitário Especial Indígena, DSEI). These group together service delivery structures and referral networks around contiguous or socioculturally related indigenous territories which often cross state as well as municipal boundaries. Each DSEI has a number of Multidisciplinary Indigenous Health Teams (Equipes Multidisciplinares de Saúde Indígena, EMSI), generally consisting of several villagebased indigenous community health workers (Agentes Indígenas de Saúde, AIS) who are supported by a nurse, dentist and nursing auxiliary working out of a Base Unit (Pólo Base) located in a central village or nearby town. The DSEI is managed by a District Head supported by a varied mix of health professionals and other specialists. Planning and performance are overseen by a District Indigenous Health Council (Conselho Distrital de Saúde Indígena, CONDISI) consisting of managers, health professionals and indigenous representatives, with the latter making up 50 per cent of the CONDISI's membership.

\subsection{Nutrition, food security, social protection and indigenous peoples}

Food security and the fight against hunger and undernutrition have long been the focus of civil society mobilisation in Brazil, but they became national policy priorities in 2003, when Luis Inácio Lula da Silva took office as president and launched the 'Zero Hunger' (Fome Zéro) strategy. Lula's government initially struggled to manage its profusion of social programmes effectively to deliver significant reductions in poverty and undernutrition. However, this changed after January 2004, with the creation of the Ministry of Social Development and the Fight against Hunger (Ministério do Desenvolvimento Social e do Combate à Fome, MDS) and the unification of a range of benefits under a single flagship social protection initiative, the Bolsa Família (Family Stipend) conditional cash transfer programme.

Bolsa Família is a highly targeted benefit that currently reaches 13.5 million of Brazil's poorest households with cash grants of up to $\mathrm{R} \$ 306$ (approximately US\$150) per month, delivered via cash withdrawals against an ID card given to a named family member (usually the mother) and linked to a household profile on a comprehensive national database, the Single Registry (Cadastro Único). Access to these grants is subject to a number of 'conditionalities' including antenatal checkups, children's school attendance, immunisation and growth monitoring. Recording of data on compliance with these conditionalities is the responsibility of local governments, via monitoring systems maintained by municipal education, health and social assistance secretariats.

Among indigenous peoples and their allies, there have been longstanding concerns with the food security of communities affected by loss of territory and disruption of traditional livelihood systems. These concerns found expression in the first National Forum on Food Security, Nutrition and Sustainable Development for Brazil's Indigenous Peoples, held in 2003, as a result of which FUNASA established a specific nutrition programme for indigenous peoples and released a package of technical nutrition monitoring guidance for DSEI health teams (FUNASA 2005).

The following year a new Basic Law on Food and Nutritional Security was promulgated, providing a legal framework for the national Food and Nutritional Security System (Sistema de Segurança Alimentar e Nutricional, SISAN) and its monitoring system SISVAN, which is discussed below. This was followed in 2010 by an amendment which enshrined the right to food in Brazil's Constitution. 
In recent years, as social indicators have improved rapidly among the majority of the poor, particularly in urban areas and high-potential agricultural zones experiencing rapid economic growth, the Brazilian government has focused increasingly on hard-to-reach groups. After a series of high-profile food security crises hit indigenous peoples including the Guarani and Xavante, the MDS made a concerted effort to increase Bolsa Família enrolment among indigenous households. By the end of 2007, a total of 62,134 indigenous households had been enrolled by the Single Registry and 53,588 were in receipt of Bolsa Família payments (Paes de Sousa et al. 2009). While the effects of Bolsa Família on food security and nutritional status among poor households in Brazil have been demonstrated to be strongly positive, no specific national-level studies have been carried out to examine its impacts on indigenous communities. Anecdotal evidence suggests a mix of positive outcomes with negative ones, as access to the benefit strengthens the position of indigenous women and broadens indigenous households' asset bases, while the influx of cash into largely non-monetised indigenous economies accelerates the commodification of social relations and risks disrupting traditional reciprocity-based livelihood systems and exchange networks (Shankland 2011).

Following the election of Lula's successor Dilma Rousseff as president in 2010, the government's emphasis on reaching marginalised groups including indigenous peoples - in social policy has intensified. The new government's flagship strategy, Brasil Sem Miséria (Brazil Without Absolute Poverty), includes a raft of measures specifically targeting indigenous peoples as well as other hard-to-reach groups such as street dwellers and quilombolas (rural afro-Brazilian communities descended from escaped slaves).

\section{The case study}

\subsection{The Xavante Special Indigenous Health District}

The case study set out to examine the current and potential capacity to support Real Time Monitoring for the Most Vulnerable (RTMMV) of two systems operating under the auspices of Brazil's Indigenous Health Care Subsystem (SASI): the Indigenous Health Care Information System (Sistema de Informações da Atenção à Saúde Indígena, SIASI) and the Food and Nutrition Surveillance System for Indigenous
Peoples (Sistema de Informações da Vigilância Alimentar e Nutricional Indígena (SISVAN-I). As noted in Section 1, the study was designed to combine national-level analysis of these systems and their policy context with an examination of the experience of their implementation in a specific set of indigenous territories. The territories selected were those inhabited by the Xavante people in the mid-western state of Mato Grosso on the southern edge of the Amazon region. This choice of field site had been influenced by two factors: the occurrence of a highly publicised health and nutrition crisis among the Xavante people, whose infant mortality rate was already among the highest in Brazil (Guimarães de Souza et al. 2010); and the fact that the UNICEF team had carried out some work in the Xavante Special Indigenous Health District (DSEI) in the wake of this crisis which included training provision and the distribution of equipment that could be used in nutritional status monitoring.

The Xavante are a Gê-speaking people who traditionally inhabit an extensive area of the central Brazilian savannah belt, or Cerrado. The DSEI covers some 15,000 Xavante people who live scattered across 11 different municipalities in Mato Grosso state. Xavante society is intensely politicised, with social organisation revolving around a complex system of moieties positioned in permanent rivalry; political disputes often lead to territorial fragmentation, as villages split and re-form (Guimarães de Souza 2008). Relations with outsiders are frequently confrontational, drawing on invocations of the famous Xavante warrior tradition, but during a long and often violent history of contact with non-indigenous society they have also been drawn into complex political relationships with outside actors (most notably the government Indigenous Affairs Agency, FUNAI, but also other government departments and national and international NGOs), in which both traditional chiefs and younger leaders have acted as intermediaries for externally driven projects in order to secure access to trade goods and other sources of power (Santos et al. 1997).

In order to provide primary health services for the approximately 160 Xavante villages located within its coverage area, the DSEI is organised around six Pólos Base and 25 village-level health posts staffed by AIS. Higher-complexity cases are 
referred to SUS hospitals in larger municipalities. Referred patients are supported by teams based in two 'Indigenous Health Houses' (Casas de Saúde do Índio, CASAI).

\subsection{Current context and case study process}

In recent years increased mortality of Xavante children linked to undernutrition and heightened vulnerability to infectious disease has generated great anger and political mobilisation among the Xavante communities and considerable publicity at the regional and national levels. The Brazilian government has responded with a combination of emergency social assistance (including distribution of food rations), intensified efforts to enrol the Xavante in social protection programmes (including Bolsa Família) and deployment of additional health staff to the DSEI, usually on a short-term basis. In 2010-11 this government response was supported by UNICEF Brazil via training provision and the donation of equipment for use in nutritional status monitoring.

Despite these efforts, the DSEI's ability to establish a more sustainable and long-term response has been hampered by political and administrative instability. Staff turnover has been high; as in other DSEIs, Pólo Base health professionals are often relatively inexperienced and from urban areas of Brazil where levels of awareness of indigenous cultural and social realities are very limited, and few have benefited from specific training to prepare them for working in intercultural settings. This was aggravated by SESAI's decision in 2011 to switch the service contract to provide human resources for the district to another provider.

Indigenous leaders angered by service delivery failures and/or by the refusal of managers to provide access to resources at the level they had come to expect after decades of clientelistic negotiations with FUNAI and other government agencies have repeatedly mobilised protest demonstrations. The most recent of these led to the occupation of the DSEI headquarters shortly before the case study team was due to visit the area. With political tensions running high both locally and in Brasília, SESAI refused permission for the planned case study field visit on safety grounds (like some other indigenous peoples in Brazil, the Xavante have a history of taking nonindigenous health professionals hostage during protests). The study methodology was therefore adjusted to draw on a combination of publicly available data, documents provided by SESAI and interviews with SESAI and MDS staff, independent specialists and indigenous representatives who were familiar with the monitoring systems involved and/or the situation in the Xavante DSEI.

\section{Indigenous health and vulnerability monitoring systems}

\subsection{The Indigenous Health Care Information System} (SIASI)

The Indigenous Health Care Information System (Sistema de Informações da Atenção à Saúde Indígena, SIASI), a SASI-specific system operated by SESAI, was initially developed by FUNASA under the World Bank-Ministry of Health VIGISUS (Disease Surveillance and Control) programme. It consists of a number of different modules, the first of which to be established was demography - essentially a registration database of the population covered by the DSEI, completed during an initial census and intended to be updated with recording of births and deaths. Version 2.0, introduced in 2002, included additional modules for morbidity and immunisation, and version 3.0 added modules for sanitation and oral health, with women's health and nutrition surveillance scheduled for inclusion in Version 4.0 (Paes de Sousa et al. 2009).

SIASI began life in 2000 as an online system, but in the face of the severe connectivity problems experienced by many DSEIs located in remoter regions, it subsequently shifted to a mixed online/offline format, with data recorded on paper, then transferred to a computer and recorded on different media (usually CDs) and sent for input to 'SIASI Web' at the Pólo Base, DSEI headquarters or national level depending on the availability of reliable internet access (Sousa et al. 2007). The increased availability of internet-connected computers in the DSEIs and Pólos Base has led to a shift back towards a more fully online model in SIASI 4.0, which was launched in August 2012.

\subsection{Food and Nutrition Surveillance Systems (SISVAN/ SISVAN-I)}

The Sistema de Informações da Vigilância Alimentar e Nutricional (Food and Nutrition Surveillance System, SISVAN) is a national system which has evolved since the 1990s with support from UNICEF and other agencies, and 
Table 1 Indigenous population of Xavante DSEI municipalities - census and SIASI

\begin{tabular}{llll}
\hline Xavante DSEI & Census 2010 (IBGE) & SIASI 2010 (version 3.0) & SIASI 2012 (version 4.0) \\
\hline Municipalities & $\begin{array}{l}\text { Rural population } \\
\text { self-identifying as } \\
\text { indigenous }\end{array}$ & Indigenous people & Indigenous people \\
\hline Agua Boa & 243 & 222 & 3,095 \\
Barra do Garças & 3,366 & 3,286 & 3,729 \\
Bom Jesus do Araguaia & 0 & 725 & 794 \\
Campinápolis & 7,589 & 5,703 & 6,542 \\
Canarana & 1,078 & 1,505 & 0 \\
General Carneiro & 1,426 & 1,260 & 1,911 \\
Nova Nazaré & 1,171 & 1,131 & 0 \\
Novo São Joaquim & 57 & 81 & 0 \\
Paranatinga & 1 & 694 & 729 \\
Poxoréo & 486 & 423 & 0 \\
Santo Antonio do Leste & 528 & 269 & 0 \\
\hline Total & 15,945 & 15,299 & 16,800 \\
\hline
\end{tabular}

Source Authors' compilation based on data from IBGE and SIASI.

since 2003 has been used to monitor the implementation and impact of the national food security strategy. It includes growth monitoring data that are collected by the SUS primary care providers at the municipal level, both routinely and as part of targeted programmes linked to the Bolsa Família conditionalities (Caldas and Santos 2012). This information is uploaded to the national system by municipal health secretariats, via an online interface operated by DATASUS.

Following a series of high-profile cases of spikes in indigenous infant mortality linked to food insecurity, and a resolution adopted at the 2006 National Indigenous Health Conference, FUNASA committed to developing and implementing a food and nutritional security strategy. It developed a specific system, the Food and Nutrition Surveillance System for Indigenous Peoples (Sistema de Informações da Vigilância Alimentar e Nutricional Indígena, SISVAN-I) which followed the SISVAN data collection protocols but functioned separately, as it lacked both an online interface and interoperability with the DATASUS system. At the time of the study the SISVAN-I functioned entirely via paper forms and collation of Excel spreadsheets, but its inclusion as an online SIASI module is now under way as part of the SIASI 4.0 rollout.

\section{Case study findings}

\subsection{Quality of information}

Unlike the systems managed by the mainstream SUS information department (DATASUS), which generally enable non-registered users to generate detailed reports online, SIASI data access and analysis is highly centralised and records are hard to cross-reference with other sources. Although SESAI staff members from the department's Brasília headquarters were able to meet the study team and explain the functioning of the health information and nutrition monitoring systems, the team was not given access to sufficient disaggregated data to be able to assess the information quality of the SIASI modules for morbidity, immunisation, sanitation and oral health. The quality of the SIASI's most accessible component, its population database, is generally considered to be relatively high, and certainly more reliable than the population records formerly kept for different indigenous communities by FUNAI (Azevedo 2009). However, when it comes to the breakdown by 
municipality - a key issue for the integration between the SASI and the mainstream municipality-based SUS - there are considerable discrepancies not only between the census data for the indigenous population of different areas and the SIASI figures, but between the population data recorded in different SIASI versions. Table 1 compares the census and SIASI figures for the indigenous population of the municipalities that fall within the coverage area of the Xavante DSEI.

While the overall difference in SIASI population figures for the DSEI between 2010 and 2012 could be due to a combination of population growth and improved registration coverage, the major discrepancies in numbers for specific municipalities - with some apparently losing their indigenous population altogether while others gain a vastly increased number - suggests that the system for attributing each village to a particular municipality has undergone some radical changes. The comparison between census and SIASI figures for 2010 reinforces this conclusion, since the total population figure is similar but some municipal figures are wildly different.

This is problematic when the link with the municipalities is a key issue for both interoperability with DATASUS systems and analysis of trends over time. Garnelo et al. (2005) have demonstrated the potential for using GIS analysis of SIASI data to generate analysis of health inequalities affecting indigenous peoples at both the macro and micro levels, but fulfilling this potential will clearly require SIASI to implement a more consistent approach to geo-referencing.

The challenge of recording and analysing georeferenced data on indigenous health and nutrition in a way that integrates the territorial logics of the SUS and the SASI is a significant one. Formally recognised indigenous territories often extend across both state and municipal jurisdictions, and an individual indigenous person registered in the SIASI may be living in a village within such a territory, in a village outside the territory's boundaries, in an urban area or in a different kind of settlement, such as an informal encampment in a land conflict area.

Furthermore, indigenous people tend to be highly mobile, moving between villages to maintain family links or fulfil social obligations and engaging in circular migration patterns between indigenous territories and urban areas in search of economic opportunities or access to services such as health and education. In addition to the need to refer to medical records when an indigenous patient seeks a consultation, the high prevalence among indigenous people of diseases such as TB which are spread by interpersonal contact makes it essential for health services to be able to track individuals and identify their contacts. Currently, the absence of systematic guidance on recording of individual names and ethnic identities makes it difficult to identify patients who are away from their home villages, and increases the likelihood of duplicate entries in the system (Paes de Sousa et al. 2009).

Frequent updating is a key element in the usefulness of data for RTM, and among indigenous peoples the high levels of mobility, as well as high birth and mortality rates, make this all the more important. The frequency with which data are uploaded varies considerably from DSEI to DSEI. In 2010, 80 per cent of DSEIs submitted their information to the central SIASI database managers at least on a monthly basis, but 8 per cent did not have a regular update timetable, and key informants reported cases of events such as births, vaccinations or consultations being recorded with the date that information from paper records was uploaded to the system (usually to meet an update deadline set in Brasília) rather than the date on which they took place.

On the nutritional status monitoring side, the study team was not given access to the Excel sheets used for consolidating SISVAN-I data and could not therefore assess the quality of data for the Xavante DSEI. SESAI reports a good level of system coverage (i.e. a high proportion of indigenous children registered with the SISVAN-I system), but interviews indicated that regular data collection is the exception rather than the rule in many DSEIs. In the Xavante DSEI a wellfunctioning system of growth monitoring data collection by village-based AIS, backstopped by the EMSI professionals and supervised by three nutritionists based in different parts of the DSEI, appears to have ground to a halt as a result of the recent management changes. A large number of EMSI professionals have left, and a staffing reorganisation has abolished two of the three nutritionist posts. At the time of the case study, the protest occupation of the DSEI headquarters 
made it impossible to ascertain whether data from all the AIS was still being passed on to the DSEI-level information system administrators for inclusion in the consolidated Excel sheets.

In the mainstream SISVAN system, growth monitoring data is regularly collected and uploaded to the national system as part of each municipality's fulfilment of its obligations for Bolsa Família administration. However, analysis of publicly available data suggested that this record is incomplete, as several municipalities which both census and SIASI data show to have indigenous populations have failed to record any growth monitoring data for indigenous children in recent months. This, in turn, suggests that municipal health secretariats either are not engaging in outreach activities to ensure that indigenous households are enrolled as Bolsa Família recipients or are failing to monitor whether they are fulfilling the programme's conditionalities - something which would require them to exchange data with the DSEI, as the body responsible for provision of the relevant services in the Xavante villages.

\subsection{Inclusivity}

Effectively promoting inclusion of marginalised minority groups requires both expansion of services and their adaptation to the specific circumstances of these groups, addressing the social, cultural, economic, geographical and political determinants of their marginalisation. The fact that Brazil has not only enshrined a rights-based approach to universal access but also recognised the particular vulnerability of its indigenous population and put in place robust policy and legal frameworks for targeted indigenous health, nutrition and social protection services, backed by a considerable investment of resources, indicates a very strong commitment to inclusivity. The country has made considerable strides in expanding access to services among the poor, and indigenous peoples have gained from this general commitment, with higher levels of access to primary health care and increasing enrolment in conditional cash transfer programmes. However, the level of progress on adapting systems to reflect the diverse realities of Brazil's indigenous peoples remains uneven.

On the one hand, the creation of the SASI, the organisation of services in DSEIs rather than according to the municipality-based model and the development of tailored information systems such as SIASI and SISVAN-I reflect a strong commitment to designing systems to fit the realities of indigenous peoples. On the other, it could be argued that this emphasis on standalone solutions has distracted attention from the need to ensure inclusivity by adapting the existing systems covering mainstream service delivery - especially those administered by DATASUS to reduce the 'problematic demographic and epidemiological invisibility' of indigenous peoples identified by Coimbra and Santos (2000: 131). Given the need to ensure both adequate referral support from the mainstream SUS to the DSEIbased primary care system and effective integration of SASI service delivery with the conditionalities of the mainstream social protection system, the current low level of interoperability of SIASI and SISVAN-I with their DATASUS counterparts is highly problematic.

Inclusive and effective RTM coverage requires that service providers are able not only to reach marginalised populations living in remote areas but also to record and transmit the data collected during their work with them in a timely manner. The study team was not given access to information on staffing levels for individual DSEIs or detailed breakdowns of personnel and equipment availability for the Xavante DSEI, our case study site. However, we were given extensive briefings on the technological strategies being used both to improve connectivity in the DSEIs to strengthen the RTM potential of SIASI and SISVAN-I and to promote these systems' integration with DATASUS.

\section{The SIASI version in use in most of the DSEIs} (3.0) was developed in Delphi and uses the Interbase relational database management system. This feeds into the national level Oracle ASP-based SIASI web system, which is now being standardised as the basis for SIASI 4.0 at both the national and DSEI levels. SIASI is also beginning to use a Data Warehouse implementation to permit integration with the DATASUS systems.

Currently, all 34 DSEI headquarters have access to broadband (ADSL) data connections, but only 143 (41 per cent) of the Pólos Base are similarly equipped. In the Xavante DSEI, only one of the six Pólos Base has a broadband connection. The quality of these connections is highly variable, and several DSEIs reported suffering frequent offline 
- No link from DSEl to municipal social protection departments

- No SISVAN-I/SISVAN web interface

- Centralised data analysis and long delays in management response

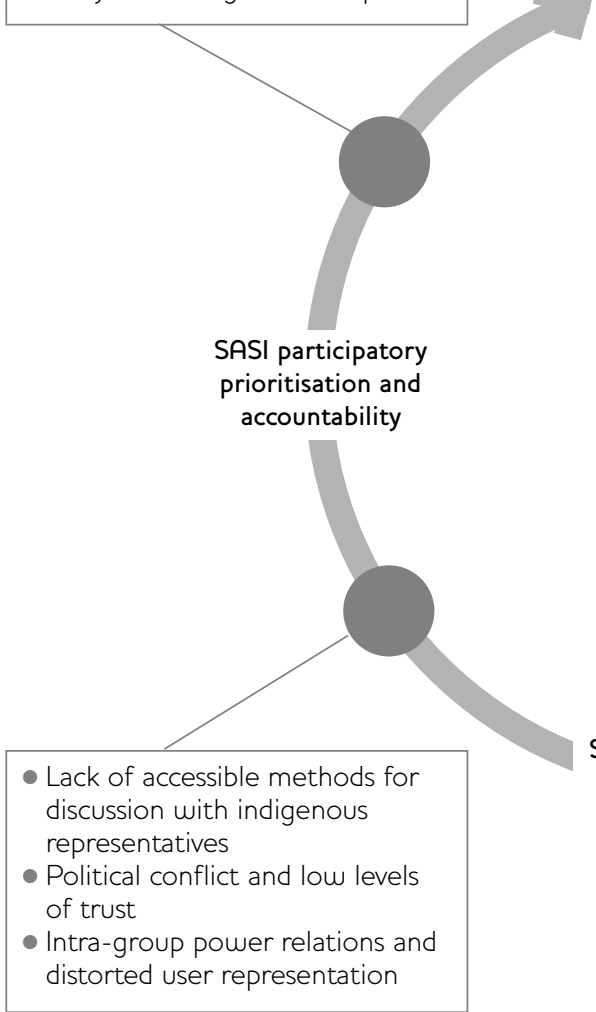

SASI health + SUAS social protection response
- Low presence of municipal structures in remote villages

- No access of VHUs to municipal registries

- No Cadúnico/SSI interface
SASI health team local analysis

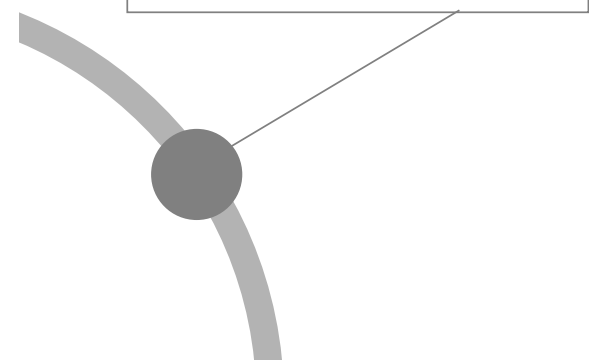

SASI village and $\mathrm{HW}$ data collection

Source Authors' compilation from key informant interviews.

periods and equipment breakdowns. Conditions at the village health post level are even more challenging, with most lacking even a reliable electricity supply and depending on solar batterypowered two-way radios for communication. SESAI has plans to experiment with the use of the $3 \mathrm{G}$ capable palmtop computers in field-based data collection, initially used for Brazil's 2010 Census, but timely data uploading is likely to continue to be a challenge given limited mobile phone network coverage, particularly in sparsely populated areas of the Amazon where health teams can take several weeks to visit all the scattered villages located within the coverage area of a Pólo Base.

The difficulty in reaching remote outlying villages affects many districts in the northern and midwestern regions of Brazil, including the Xavante
DSEI. Not only is it harder to retain nonindigenous staff in the remoter Pólos Base, but the fact that many villages are often accessible only by boat or on foot along forest trails means that they are particularly badly affected by the administrative problems to which DSEIs are frequently subject: delayed funding transfers and slow and bureaucratic procurement processes can lead to frustrating delays in obtaining spare parts for off-road vehicles and boats, and even fuel and food for long periods away from the Pólo Base, which in turn can mean that EMSI professionals are unable to maintain vaccination schedules or ensure regular collection of growth monitoring data. This raises issues for the equity and inclusiveness of RTM systems, as it means that DSEI-level aggregate figures are more likely to give disproportionate weight to data reflecting the 
realities of more easily accessible villages, which already have better access to services than their remoter counterparts.

\subsection{Relevance to potential users}

Given that Brazil's Indigenous Health Care Subsystem (SASI) emphasises decentralisation to the district (DSEI) level and oversight by district health councils (CONDISIs) with significant service user representation, potential users of RTMMV data include not only national-level health system managers but also DSEI heads and their supporting technical specialists (including nutritionists) and the indigenous leaders who represent their communities on the CONDISIs. Recognising this, a wide-ranging consultancy study carried out under the World BankMinistry of Health VIGISUS programme before the creation of SESAI recommended integration of SIASI with management systems at all levels of the SASI (Paes de Sousa et al. 2009). Although this recommendation was accepted, it was never implemented.

In addition, while health care provision and health and nutritional status data collection for indigenous peoples is the responsibility of the SASI, administration of social protection systems including Bolsa Família and its associated conditionality compliance monitoring is the responsibility of municipal secretariats reporting to the MDS under the Unified Social Assistance System (Sistema Único de Assistência Social, SUAS). This means that potential users of RTM data from indigenous territories also include managers of the social protection system from the municipal to the national level.

Examination of official documents and interviews with key informants working at different levels of the SASI and the MDS made it possible to reconstruct the desired information flows for RTMMV and their corresponding policy responses, and identify several points within these flows where the current functioning of the system is particularly problematic. These points and their relevance to key issues for RTMMV are presented schematically in Figure 1 and discussed below.

\section{(a) SASI plus SUAS system management and data collection by village-based AIS}

In the Xavante DSEI, as in other indigenous health districts, village-based indigenous health workers (AIS) provide the backbone of RTM data collection on nutritional status and other indicators of vulnerability among indigenous children. They carry out routine growth monitoring, birth/death recording and epidemiological surveillance activities using equipment provided by UNICEF and SESAI, and record the data on paper in notebooks and/or printed forms. They are supervised by EMSI professionals reporting to the SASI, with no institutional links to the municipal secretariats responsible for monitoring compliance with the Bolsa Família conditionalities. Municipal services, including the primary care services of the mainstream SUS, are virtually non-existent in indigenous territories and particularly in the remoter villages. Indigenous people wishing to collect their Bolsa Família payments or matriculate their children in school must travel to an urban centre, which may involve long journeys on foot or by dugout canoe. AIS are not authorised either to provide data to municipal service managers or to consult municipal registries, for example to see who in their village is registered as a Bolsa Família beneficiary and cross-check their household profile in the CadÚnico (Single Registry) with the data held by the DSEI.

\section{(b) Data collection by village-based AIS and initial data analysis by SASI health teams}

The data collected by village-based AIS is supposed to be handed over to EMSI health professionals during regular supervision visits, and taken back to the Pólo Base for cleaning and transfer from paper to electronic (Excel spreadsheet) form. EMSI staff are supposed to have regular situation analysis and planning meetings with the AIS from their coverage area and the indigenous leaders who make up the Local Indigenous Health Council (Conselho Local de Saúde Indígena, CLSI). Best practice guidelines suggest the use of 'Situation Room' methodology, using large-scale maps to identify spatial patterns of undernutrition or illhealth (Consórcio IDS-SSL-Cebrap 2009). This means that there should be opportunities for locallevel analysis and identification of nutritional vulnerability issues, leading to a swift and appropriate response to those identified.

In practice, however, it appears that in the Xavante DSEI - as elsewhere in the SASI - high levels of staff turnover, procurement delays or non-arrival of funding transfers have compromised routine supervision visit schedules and consequently led 
to disruption of the system of regular collation of data at the Pólo Base level (SESAI 2011). In Amazonian DSEIs where extreme seasonal variation in water levels determines whether or not DSEI boats can reach the remotest upriver villages, data may only be collected once every two or three months, and connectivity limitations mean that AIS lack the means to transmit the data they collect between supervision visits.

\section{Staff turnover also affects the ability of EMSI} professionals to develop an understanding of the local cultural context and build up a relationship of trust with the indigenous population, including the leaders who make up the membership of the CLSI and potentially play a key role in interpreting any trends identified in the data and mobilising community responses. This significantly weakens the scope for quick, appropriate and effective response to issues identified through RTM, which should be one of the strengths of the decentralised and participatory primary care model of the SASI.

\section{(c) Initial data analysis by SASI health teams and} epidemiological analysis and priority-setting at the DSEI level

Once it has been collated, data for each Pólo Base coverage area should be passed on by the EMSI health professionals to the monitoring units in the DSEI headquarters for uploading to the online SIASI database and insertion into the DSEI-level aggregate spreadsheet for the SISVAN-I system. Integration of data from the different Pólos Base should allow district-level managers to identify priorities for immediate response or longer-term DSEI planning.

\section{Three-year district plans and annual} implementation plans and budgets are drawn up by DSEI management in consultation with indigenous leaders via the CONDISI system. Since the CONDISI also scrutinises reporting and accounts for the DSEI, this should allow for high levels of participation, accountability and responsiveness in planning, priority-setting and implementation - potentially an ideal institutional context for effective RTMMV. In practice, a number of factors mean that this potential is infrequently realised within the SASI.

Some of these factors are administrative and technical. The SASI's formal commitment to management autonomy at the DSEI level has yet to be fully followed through in practice, so locally defined plans and priorities may be overruled by managers in Brasília, and implementing CONDISI decisions may require a lengthy procurement process managed from outside the DSEI. The information systems themselves are designed for centralised rather than district-level analysis, which severely restricts their usefulness as district management tools (Paes de Sousa et al. 2009). In addition, the fact that they have not had geo-referencing built in from the outset limits their potential for micro-spatial analysis of health and nutrition indicators and their social determinants (Garnelo et al. 2005). As a result, the offline 'Situation Rooms' used by some DSEIs cannot easily be cross-referenced with a GISbased online equivalent.

However, the case of the Xavante DSEI suggests that the key determinants of the failure to fulfil the promise of participatory priority-setting linked to RTMMV are not only technical and administrative but also social and political. Bridging the cultural gulf between indigenous representatives and non-indigenous professionals requires skills that not all health system managers possess; even where indigenous people have a good command of Portuguese (which is not the case in all DSEIs) managers' and medics' use of technical, jargon-filled language can silence and exclude them (Shankland and Athias 2007). The SASI has run many training sessions for indigenous CONDISI members, but made less effort to train managers to understand indigenous cultures and use accessible language.

When the DSEI has a history of political conflict both within the indigenous population and between indigenous people and outsiders it can be very hard to secure the levels of trust necessary to have a frank and open discussion of what are often highly emotive issues. In cultural-symbolic terms the tendency of indigenous political representatives to see negotiating with the 'white state' as a form of warfare is marked in many DSEIs, and this carries over into political practices (Shankland 2010). This is certainly the case with the Xavante DSEI, where in recurrent cycles of political mobilisation leaders have mixed genuine anger (especially at the fact that high levels of avoidable child deaths have persisted despite all the promises made to them) with manoeuvring for political and material advantage against both indigenous rivals and the bureaucrats of the SASI. 
The fact that the DSEI is seen as a source of power and prestige also means that indigenous representation on the CONDISI tends to be dominated by politically active Xavante men, whether traditional chiefs or ambitious younger leaders. This is problematic for participatory RTMMV, since the most vulnerable groups (indigenous women and children, the inhabitants of remoter villages and more marginalised clans or ethnic groups) tend to be under-represented in CONDISIs.

\section{(d) Epidemiological analysis and priority-setting at the DSEI level and SASI plus SUAS system management response}

The DSEI headquarters provides a link not only with the central level of SESAI management in Brasília, but also with the municipality-based social protection system organised under the SUAS. In the case of the Xavante DSEI, analysis of available data suggests that this link is not functioning regularly or effectively.

Modifications currently being implemented in SIASI's version 4.0 have increased the scope for RTM interoperability with the mainstream SUS and SUAS. These include adding fields for inclusion of registration numbers for the CadÚnico social protection registry and Cartão SUS health system registry. The relative comprehensiveness of the SIASI demographic module register of each DSEI's indigenous population should ensure a good level of inclusion as these schemes are rolled out. This, in turn, should improve referral and patient tracking, given the large number of indigenous people who currently lack national ID documents.

However, if it is indeed the case that there is very little dialogue and collaboration between SASI managers responsible for the DSEI-based health and nutrition services on the one hand and officials responsible for social protection programmes within the municipality-based SUAS system on the other, technical solutions such as those outlined above can only go so far towards addressing the problem.

Ensuring an effective and coordinated health and social protection response to situations of vulnerability identified through RTM with indigenous peoples requires a combination of administrative vision and political will to establish incentives for managers responsible for what are effectively parallel systems to engage in systematic collaboration.

Some of the necessary political will could come from indigenous peoples themselves, as their political representatives use spaces such as the CONDISI planning and evaluation meetings to insist on greater coherence in the services provided to their community. However, although several CONDISI representatives have shown an interest in pursuing this issue, indigenous leaders interviewed by the case study team were pessimistic about the overall state of participation in the SASI. They felt that a combination of political divisions, cooptation and discouragement in the face of long delays in fulfilling promises made by SASI managers had undermined the effectiveness of once-powerful social movements.

While effective bottom-up pressure to improve system performance is currently lacking, topdown pressure to deliver is building as a result of the government's high-profile commitment to the Brasil Sem Miséria (Brazil Without Absolute Poverty) agenda. In June 2012, President Dilma Rousseff announced the establishment of an interministerial task force to improve the health and nutritional status of the indigenous population, and launched an action plan to tackle infant and maternal mortality in 16 DSEIs where the situation is considered to be particularly critical, including the Xavante DSEI. Under the action plan, an emergency intervention was launched in the Xavante DSEI in July 2012, with a series of activities that included simultaneous collection of nutritional status data in all six of the DSEI's Pólos Base. The case study team has not been given access to this data, but assuming that a good coverage level was achieved it could potentially provide an excellent baseline for future RTMMV in the DSEI - if, that is, a reversion to the past pattern of disruption by staff turnover and political turbulence can be avoided.

\subsection{Costs and sustainability}

No data on costs was made available to the case study team during the research. Previous studies have shown that the per capita costs of providing primary care to indigenous communities within the SASI are up to five times greater than the average for the mainstream SUS (Consórcio IDS-SSL-Cebrap 2009). Nevertheless, there appears to be a political consensus that this level 
of spending is justified both by the technical and management challenges involved and by the glaring inequalities in health status between indigenous and non-indigenous Brazilians.

The development costs of SIASI, funded mainly from World Bank loans, were undoubtedly high. However, now that it is located within a department of the Ministry of Health $(\mathrm{MoH})$ and making progress towards DATASUS integration, it seems safe to assume that meeting the cost of future updates will not be a problem, given its relatively insignificant scale in comparison with the rest of the massive and well-resourced DATASUS system.

Overall, sustainability does not appear to be an issue given the strength of Brazil's economy and the formidable and growing institutional capacity of its health and social protection systems. At least as long as the president remains resolutely committed to ending absolute poverty in the country, measures to reduce the vulnerability of indigenous peoples will continue to receive favourable treatment in government resource allocation.

\section{Lessons learned and next steps}

Despite the limitations in access to data, this study has afforded some insights into the specific challenges that have hampered efforts to put in place effective RTM systems in the SASI, and some lessons that have broader applicability to RTMMV work with indigenous peoples. These challenges fall into different categories: technical and technological; social and cultural; and political and institutional.

The technical and technological challenges facing RTM in the SASI include questions of geographical inaccessibility and the high levels of mobility of indigenous individuals and communities. Both pose problems for coverage and frequency of data collection, as well as for reliable geo-referencing of data. The remote areas in which many indigenous peoples live pose many practical challenges including lack of connectivity and harsh conditions that can reveal weaknesses in the robustness of technological resources designed for urban environments. The social structure of the indigenous population, divided as it is into 'micro-societies' with particular social, cultural and epidemiological characteristics, poses challenges for trend monitoring and analysis in the face of high variability across very small sub-populations.

This high level of variability also poses challenges for interoperability, when tailor-made systems like the SIASI try to integrate with mainstream systems like those managed by DATASUS, which have been designed to ensure RTM of a small number of standardised variables across populations that are both much larger and more homogenous. SESAI is currently trying to address the challenge of interoperability and break out of its system enclave path-dependence by combining the introduction of standard fields such as the Cartão SUS number with data mining/business intelligence strategies.

While some challenges result from design choices that were made without considering interoperability (such as the use of different age ranges for the variables in SIASI and DATASUS), others are more inherent in the nature of work with indigenous peoples. The latter include the need to establish robust identification protocols to deal with situations where an individual may have multiple names (some of which are secret and cannot be shared with outsiders), or may change names after an important life event such as puberty.

The social and cultural challenges centre on issues of intercultural communication. Brazil's commitment to participation in decentralised health system planning and oversight through structures like the CONDISIs can only fulfil its great potential as an entry point for RTM if data and analysis tools are adapted and managers are trained to work effectively across different cultural contexts. This includes sensitivity to the fact that concepts like 'health', 'nutrition' and 'monitoring' that are assumed to be universal in Western societies do not necessarily map automatically onto analogous concepts within indigenous cultures. Indigenous people may, for example, associate 'health' with access to land, 'nutrition' with the observance of food taboos or 'monitoring' with the practice of spying on enemies (cf. Shankland 2010).

The political and institutional challenges overlap with the social and cultural ones, since intercultural communication skills are necessary to overcome the often entrenched mistrust and hostility to the 'white state' that has resulted 
from indigenous peoples' experiences of colonisation, displacement and exploitation. A targeted health care system like the SASI can begin to address these issues by establishing clear channels of communication, such as the CONDISIs. However, the need to integrate with mainstream services brings other challenges in large and highly unequal countries like Brazil, where despite strong policy-level commitment to ensuring respect for minority groups and traditional knowledge, the local officials overseeing mainstream health or social protection services may still need further support to overcome attitudes to indigenous peoples that reflect a centuries-old legacy of discrimination and prejudice.

Political challenges also exist within the state machinery, where dedicated agencies dealing with indigenous affairs may find themselves locked in turf wars with sectoral ministries responsible for the services - such as primary health care and social protection - that indigenous peoples are trying to access. In Brazil, SESAI is perceived as something of an enclave within the $\mathrm{MoH}$, perhaps as a result of attitudes inherited from its closed and secretive predecessor institution, FUNASA. Given that it is dealing with the consequences of a complex transition and still mainly focused on establishing its internal structures, SESAI has found it hard to develop outward-looking agendas with other government departments, such as MDS, as well as with external partners.

While assigning services to dedicated agencies risks seeing them turning into enclaves, mainstreaming raises challenges for visibility and voice within RTM. At the broader policy

\section{References}

Azevedo, M. (2009) 'Situação Demografica dos Povos Indígenas no Brasil' in Consórcio IDSSSL-Gebrap Diagnóstico Situacional do Subsistema de Saúde Indígena, Brasília: Consórcio IDS-SSL-Cebrap

Benevides, L. and Portillo, J.A.G. (forthcoming) 'A Criação da Secretaria Especial de Saúde Indígena: Participação e Negociação', Saúde e Sociedade

Caldas, A.D.R. and Santos, R.V. (2012)

'Vigilância Alimentar e Nutricional Para os

Povos Indígenas no Brasil: Análise da

Construção de uma Política Pública em level, these challenges can include ideological resistance to targeting among advocates for universal rights and access, who sometimes label arguments for equity and addressing health inequalities as 'special pleading' that risks undermining universality (Coelho and Shankland 2011). Ideology aside, bureaucratic logic can also be an obstacle, as managers responsible for well-established systems like DATASUS may be reluctant to change their protocols in order to address the specificities of a small segment of the population.

In Brazil, the high level of political priority given to the Brasil Sem Miséria agenda and the emphasis on tracking progress and measuring results provides an enabling environment for overcoming these obstacles. If SESAI can be encouraged to work cooperatively with other external and internal partners, there is great potential to strengthen RTMMV efforts in the SASI - and in particular to overcome the lack of integration between health and social protection systems. In other contexts where indigenous peoples face similar health inequalities but remain much less visible than they are in Brazil, RTMMV faces even greater challenges. Collaboration with external agencies such as UNICEF could support the government of Brazil's efforts in this area not only by providing practical assistance but also by facilitating ongoing evaluation and reflection on the lessons learned. This could help Brazil both to continue to improve its own practice and to share its experiences with other countries whose indigenous peoples face similar challenges, but whose governments have not yet shown the same level of commitment to tackling these challenges.

Saúde', Physis: Revista de Saúde Coletiva 22: 545-65

Coelho, V.S.P. and Shankland, A. (2011) 'Making the Right to Health a Reality for Brazil's

Indigenous Peoples: Innovation, Decentralization and Equity', MEDICC Review 13.3: 50-3

Coimbra Jr, C.E.A. and Santos, R.V. (2000) 'Saúde, Minorias e Desigualdade: Algumas teias de Inter-relações, com Enfase nos Povos Indígenas no Brasil', Ciência Ẽ Saúde Coletiva 5: 125-32

Consórcio IDS-SSL-Cebrap (2009) Diagnóstico Situacional do Subsistema de Saúde Indígena, Brasília: Consórcio IDS-SSL-Cebrap 
FUNASA (2005) Norma Técnica: Vigilância Alimentar e Nutricional para os Distritos Sanitários Especiais Indígenas, Brasília: FUNASA

Garnelo, L.; Brandão, L.C. and Levino, A. (2005) 'Dimensões e Potencialidades dos Sistemas de Informação Geográfica na Saúde Indígena', Revista de Saúde Pública 39: 634-40

Guimarães de Souza, L. (2008) 'Demografia e Saúde dos Indios Xavante do Brasil Central', PhD dissertation, Escola Nacional de Saúde Pública Sergio Arouca, Rio de Janeiro: FIOCRUZ

Guimarães de Souza, L.; Santos, R.V. and Coimbra Jr, C.E.A. (2010) 'Estrutura Etária, Natalidade e Mortalidade do Povo Indígena Xavante de Mato Grosso, Amazônia, Brasil', Ciência E̊ Saúde Coletiva 15: 1465-73

Oosterhoff, P.; Burns, D.; Shankland, A. and van der Kwaak, A. with López, A. (2012) Transforming Health Systems to Serve the Wellbeing of Indigenous and Minority Peoples, Amsterdam and Brighton: KIT/IDS

Paes de Sousa, R. and Menegolla, I. (2009) 'Perfil Epidemiológico das Populações Indígenas no Brasil', in Consórcio IDS-SSL-Cebrap, Diagnóstico Situacional do Subsistema de Saúde Indígena, Brasília: Consórcio IDS-SSL-Cebrap

Paes de Sousa, R.; Lucas, H. and Azevedo, M. (2009) Modelo de Monitoramento e Avaliação da Saúde Indígena, Brasília: Consórcio IDS-SSLCebrap
Santos, R.; Flowers, N.; Coimbra, C. et al. (1997) 'Tapirs, Tractors, and Tapes: The Changing Economy and Ecology of the Xavánte Indians of Central Brazil', Human Ecology 25.4: 545-66

SESAI (2011) 'Oficina de Redefinição das Estratégias de Monitoramento das Informações em Saúde Indígena, mimeo, Brasília: SESAI

Shankland, A. (2011) 'Reimagining Development with Indigenous People', IDS Bulletin 42.5: 24-9

Shankland, A. (2010) 'Speaking for the People: Representation and Health Policy in the Brazilian Amazon', DPhil dissertation, Institute of Development Studies, Brighton, University of Sussex

Shankland, A. and Athias, R. (2007)

'Decentralisation and Difference: Indigenous Peoples and Health System Reform in the Brazilian Amazon', IDS Bulletin 38.1: 77-90

Sousa, M.; Scatena, J.H.G. and Santos, R.V. (2007) 'O Sistema de Informação da Atenção à Saúde Indígena (SIASI): Criação, Estrutura e Funcionamento', Cadernos de Saúde Pública 23: 853-61

Stephens, G.; Nettleton, G.; Porter, J. et al. (2005) 'Indigenous Peoples' Health - Why are they Behind Everyone, Everywhere?', The Lancet 366.9479: 10-13

Victora, G.G.; Aquino, E.M.L.; do Carmo Leal, M. et al. (2011) 'Maternal and Child Health in Brazil: Progress and Challenges', The Lancet 377.9780: 1863-76 